\title{
Exploring Conventional Models of Purchase Intention: Consumer Attitudes Towards Smartphones Advertisement.
}

\author{
Ahmad Azaini Manaf $\cdot$ Lee Sung-Pil† \\ *Graduate School of Design, Dongseo University, Busan, Korea
}

\begin{abstract}
Mobile phone makers compete for market shares through domination in media advertisements. These include domination of advertisements (Ads) in TV and the internet. However, the abundance and complexity of the competitions of Ads in TV does not guarantee advertising success which can influence consumers' emotion and the purchase intention towards the brand. This research analyses the case of a directional model on Attitude-towards-the-Ad model as a baseline into a new proposed correlation models (MacKenzie, Scott, \&Lutz, 1989). The survey targets the involvements of Asian smartphone owners' attitude on advertisements, brands and purchase intentions. CFA (Confirmatory factor Analysis) was used in the research experiments, including hypothesis testing, the outcome of model fit which revealed significant levels and were successful. The study revealed that all three paths have consistently high coefficient paths (Attitude to Ads - Attitude to Brands - Purchase Intention), showing significant value of $(\beta=>.80)$, which supported each correlation factors. Therefore, this structural model, could set standards for creative managers and advertising teams to improve the brands visibility and build strong influences on attitudes in advertisements and improve purchase intentions.
\end{abstract}

Key words: Advertising Claim, Attitude, Brand, belief, Purchase Intention, Confirmatory Factor Analysis, Structural Model.

\footnotetext{
† Corresponding Author : Lee Sung-Pil (Department of Industrial Design, Dongseo University). This work was done by 2013 Dongseo University with sponsorship from Malaysian Ministry of Higher Education.

E-mail : sungplee@gdsu.dongseo.ac.kr

TEL : 010-326-1946
} 


\section{Introduction.}

Television is a powerful advertising medium because it uses many of the human senses and allows the advertiser to reach a larger audiences compared to other media. TV advertisements landscape, according to Leslie Haines, director of Graphic Design at the Art Institute of Tennessee (2012), is friendlier, consumer-focused and technology-rich. According to Haines, "advertisers have to compete with a tremendous amount of communication and recreation to gain viewer's attention”. In short, advertisers have to compete not only with other advertisers but also in today's digital world, with thousands of apps, online sources, laptops, tablets and smart phones. In short, people want to hear what you can offer.

Understanding the causes of an effective TV advertising, in today's complex world of media will save tremendous amount of money and create the desired consumer purchases. For an ad executive, it is imperative for the survival of a corporation to measure the success of his advertising campaign which requires an exploration of an assortment of factors. This study tries to provide insights on the causal relationships between the variables that ensure advertising success in the crowded field of smartphones marketing.

This research sets to investigate factors that led to consumer's attitude to purchase generated from the advertisements for marketing of smartphones companies, specifically LG, Samsung, iPhones and Nokia in the Asian region. The main purpose is to identify the correlation between consumer's attitude and intentions, which affected the brand and thus, literally affected the advertisements itself. The critical question asked here is how well the advertisements can influence customer to purchase? The answer lies in understanding the concept of advertising and its practices.

This study deliberated specifically on the investigations of the complex relationships between appeal stimuli of the Ad, Attitude toward the Ad (AAD) attitude towards the brand $(\mathrm{AB})$ and the Purchase Intentions (PI). The research was carried-out on a sample of 221 multi-ethnic respondents from South Korea (26\%), China (6\%) and Malaysia (67\%), using Non-probability Convenience sampling method. Examination and analysis of the relationships between the variables was done by using Structural Equation Modeling technique (SEM).

\subsection{Hypothesis development and Conceptual Model.}

Visual advertisements with certain emotional content, may promote positive emotional appeals will most likely create influence of purchasing activity. Studies on advertisements by Swaminathan (1996) and Fishbein M. (1963) posited that attitude concepts (cognitive, affect and conation) play important advertisement influence factor, such as positive attitude towards advertisement itself ; the proposed concept can be referred to as depicted in Figure 1. The construct of attitude continues to be an important focal point in the domain of media. (Fishbein \& Ajzen, 1975) defines attitude as “an individual's positive or negative feelings about performing the target behavior'’ However, a more thorough study by Lutz, further contended that the role of attitude towards advertisement is a critical indicator of advertising effectiveness (Lutz, 1985). Henceforth, in the design of an advertising visuals and content, the advertisers need to put more effort into adding information that helps consumers form positive attitudes towards it (Pyun, Kwon, Chon, \& Han, 2012).

The aim of this research is to assist visual designers as well as marketers to identify the main factors that appeal to the emotion of the consumer. The research objective is to create hypothetical framework based on Attitude, Belief and Intention as in Figure 1 and execute using confirmatory factor analysis, to identify the highest coefficient of the each factors. This model is able to assist the visual design creation and marketing field for further understanding and insights into consumer behavior. 


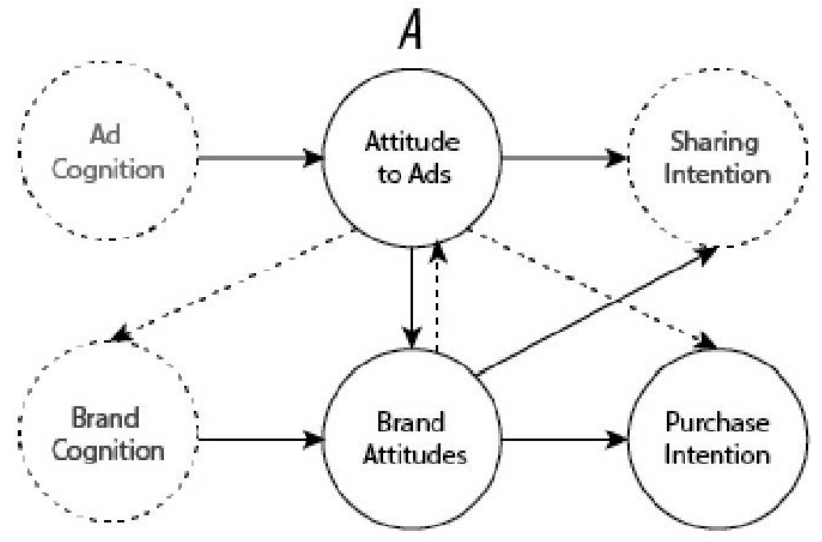

Purchase Intention Direct -Effect Models Based

Figure 1. The Direct effect of Purchase intention A, derived from baseline reference of (Lutz, MacKenzie, \& Belch, 1983; Lutz, 1975; Huang, So, \& Liu, 2012)1)

Advertising research and discussion has generally shown that the persuasive Ad campaign is to improve trustworthiness level as perceived by recipients. Recent studies consider various dimensions of target advertisement distinctiveness in competitive advertising (Keller, 1991; Kent and Allen, 1994; (Unnava \& Sirdeshmukh, 1994). Findings suggest that distinctive ad memory traces may resist memory interference and be easier to recall Impact on visuals plays significant role viewers memory, or called Ad memory traces may be distinctive due to a commercial's exposure context, execution, and brand positioning, or due to consumers' responses to the message and brand. (Unnava \& Sirdeshmukh, 1994) Observed less interference when target ads were presented in a different modality than competitive ads (e.g. in visual versus auditory form). This can be supported as with perceived credibility through multi-dimensional explanatory model which is (1) Attractiveness, (2) Expertise, (3) Trustworthiness, which are these models were receives extensive validation worldwide (Pornpitakpan, 2003).

1) Note: This is a pattern of direct-effects cognition model and the response towards purchase intention.

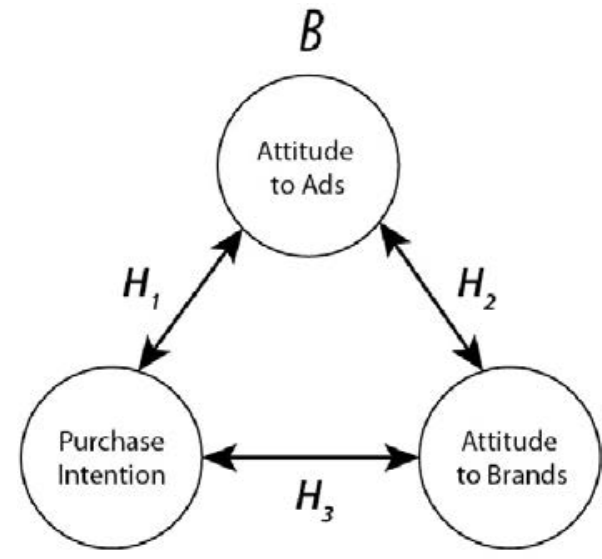

Proposed correlated Model

Figure 2. $\boldsymbol{B}$ is a proposed correlated model of purchase intention which correlates to each other.

\section{- Relationship of Attitude to Advertisement} towards Purchase Intention. AttoAds $\leftrightarrow$ PIntent

The ability to remember a commercial's content is a necessary rather than a sufficient condition for Ads effectiveness. The concept of attitude (Rosenberg \& Hovland, 1960) according to them, attitude has three concept: cognition, affect and conation. However, many scholars founds the attitude concept not necessarily based on 3, (Dillon \& Kumar, 1985; Fisbein, 1963; Fisbein \& Ajzen, 1974; Pyun, Kwon, Chon, \& Han 2012) their research founds direct dimensional construct, whereas cognition not correlated to attitude (affect) which has directly influences behavior (conation). However, attitude on advertisement discussion towards purchase effects has subjective meaning and respectively, and both attitudes have a significant influence on purchase intention(HuangJinson, SoSong, LiuXi, 2012). Impersonal attitude reflects all aspects of the purchase situation unrelated to product, whereas advertising, being one type of purchase situation, can be represented by attitude toward the advertisement (LutzR., MacKenzieS., BelchG., 1983), and thus has a significant impact on purchase intention. Researchers believes that Attitude towards advertisements (AAD) is an effective construct representing consumers general feelings of liking an advertisement, has a favorable influence on brand attitudes (AB) and Purchase Intentions (PI) (Lutz, McKenzie \& Belch 1983).

In sum the first hypothesis is constructed as: a 
successful advertisement whether it is attractive or otherwise will improve the attitude purchase intention.

H1: Advertisement affects and improve the attitude towards Purchase Intention.

\section{- Relationship Attitude to Advertisement towards the Brand. $A A D s \leftrightarrow A B$}

Consumers may unconsciously develop positive or negative feelings towards advertisement and consequently towards the advertised brands (Gardner 1985). Positive AAD experience may communicate high expectations about the using of the advertised brands, thus linking the attitude towards advertising to the attitude towards brand (AB) (Mitchell \& Olsen 1981). Theoretically, the linkage between $\mathrm{AAD}$ is a direct causal link with $\mathrm{AB}$.

As consumers gain more experience with a product or service advertisement, they correspondingly develop a deeper knowledge, and can thus form a positive attitude that encourages them to purchase the brand's product or service repeatedly in the future (Hwang \& Hyun, 2011).

Affective stimuli is a psychological term refers to all types of subjective experience that are related to feelings and emotions, such as love and disgust, fear and desire, and pride and despair (Desmet \& Hekkert, 2007). (Lutz, 1985) Critically suggest that beliefs and positive attitude towards the Ads can also mediate brands advertisements. This was also supported by sequential study the role of Advertisement (Brown and Stayman, 1992).

The second hypothesis is formulated to show the direct causal linkage between $\mathrm{AAD}$ and $\mathrm{AB}$.

H2: Attitudes towards advertising affects attitudes towards the brand.

\section{- Relationship Purchase Intention towards Attitude towards Advertisement. $P I \leftrightarrow A A D$}

"It could be expected that advertising an existing and well-known brand would lead to a more favorable attitude towards the advertisement and the brand and a more positive purchase intention than advertising a new brand (Janssens \& De Pelsmacker, 2005). Example in figure 1, Brand influence plays significant role as consumer behavior researchers argued that quality perception has not only a cognitive component but also an affective component, which represents individuals' attitudes (Compeau, Grewal, \& Monroe, 1998). In terms of psychology of consumer behavior, purchase intention is a function of cognitive and affective evaluations (Fishbein, M. \& Ajzen, 1975).

The evaluation made into causal models of cognitive response, which will affect attitude formation, thus create an influence of intention factor (Huang, So, \& Liu, 2012). This purchase attitude factor can be summarized as a reaction of post effect to advertising. Hence, the third hypothesis:

H3: Brands plays significance role on influencing purchase intention hence improves the perception towards the advertisements.

\section{Method and Process}

\subsection{Instrument of Development}

TV advertisement samples were selected from the brands that representing the flagship product of 2012 for smartphones. The consideration of the advertisements based on their best-selling and technological features. Among the advertised brands under this study were LG Optimus G, Apple iPhone 5, Samsung Galaxy S3, and Nokia Lumia 920.

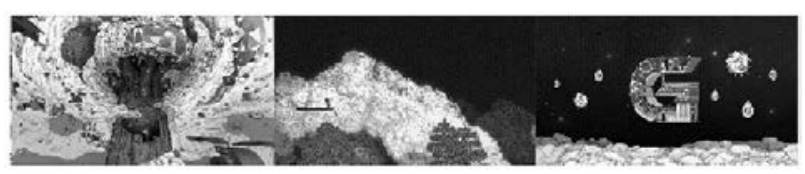

Image 1. LG Optimus G TV advertisement (LG Mobile, 2012)

\section{Advertisement 1}

The image video of advertisement 1 is a full version LG product, the Optimus G brand, an animated showcase of a colorful journey of digitally animated user riding the mobile phone as a transporter, however absence of display 
features and functionality of the smartphones is glaring.

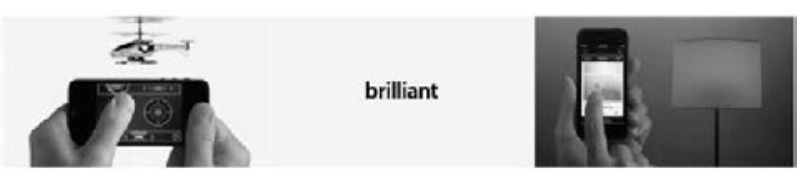

Image 2. Apple iPhone TV Advertisement - Brilliant

(APPLE, 2013)

\section{Advertisement 2}

The image 2 advertisement video, is the Apple iPhone 5 - Brilliant; a showcase of a variety of functions in iPhone models of smartphones against a white background. The visuals contain bold animated text representing functions inside the smartphones, with fingers displaying the usability interaction on the smaller screen. The video also showed a variety of controls available with the iPhone brand.

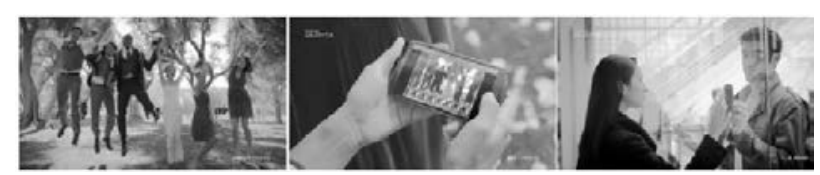

Image 3. Samsung Galaxy SIII Samsung TV advertisement: Published on June 26, 2012 (Samsung Mobile, 2012)

\section{Advertisement 3}

The Image 3 video was Samsung's Galaxy SIII, displaying lifestyle and connectivity - activities representing connections of the smartphones with people. The first scene (Best photo shots) shows smartphones capability to records multiple frame of memorable experience in a wedding; the next scene ( $S$ Beam) a romantic wedding proposal using a feature with NFC (near field communication) to exchange picture of ring. The final scene (Smart Stay) is the smartphone special feature, the use of eye tracking to shut down the smartphones.

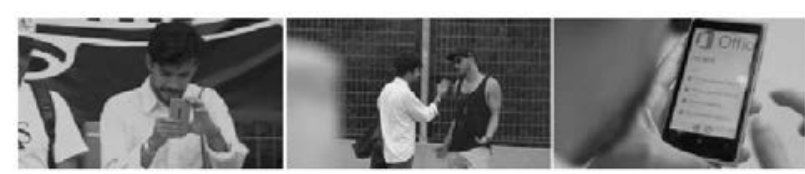

Image 4. Nokia Lumia 920 TV Ad. Work on the go with the Nokia Lumia 920 and Microsoft Office (Nokia, 2012)

\section{Advertisement 4}

The final Video of Image 4 was Nokia 920, Work on the go with Nokia Lumia 920. A shows a journalist, who uses his Nokia 920 smartphones as a reporting device, a symbolism of replacing conventional notebook and SLR camera. The scene depicts a neat multitasking situation where he is working simultaneously recording interviews, and accessing Microsoft office documents within in his Nokia.

\section{Participants and Measurement}

The instruments to measure each construct were prepared using 7-point Likert scale questionnaires. The five anchors that were used in the questionnaires were (1) strongly disagree, (2) disagree, (3) somewhat disagree (4) neutral, (5) somewhat agree, (6) agree, (7) strongly agree. The survey forms were translated into 3 different languages: Korean, Malay and Chinese Mandarin for respective market audiences. The survey and tests were conducted in Malaysia and Korea. Demographics information of the respondents, genders, age, and nationality were noted.

Testing was undertaken by assistance of Korean lecturers and Chinese $\mathrm{PhD}$ candidates in University in Southern province of South Korea. The observation tests were conducted in classroom condition; these includes distribution of 71 survey forms prepared respectively in Korean and Mandarin. In Malaysia, the surveys also involved 151 respondents that were tested under supervision of the respective institution academic instructors. The locations of the test institutional academic labs are across states, from capital city of Peninsular Malaysia, two institution Borneo of East Malaysia, and a Teacher's institute from Eastern Peninsular Malaysia. The survey designed using Adobe Lifecycle designer ES2 for customized PDF's, Microsoft Word Macro-Enabled Document in English and Malay. 
Table 1. Sample

\begin{tabular}{|c|c|}
\hline Characteristics & $\%$ \\
\hline \multicolumn{2}{|l|}{ Gender } \\
\hline Male & 32.1 \\
\hline Female & 67.9 \\
\hline \multicolumn{2}{|l|}{ Status } \\
\hline Single & 95.9 \\
\hline Married & 4.1 \\
\hline \multicolumn{2}{|l|}{ Age } \\
\hline $20-25$ & 81.9 \\
\hline $26-30$ & 12.2 \\
\hline $31-35$ & 0.9 \\
\hline $36-40$ & 1.4 \\
\hline Below 20 & 3.6 \\
\hline \multicolumn{2}{|l|}{ Nationality } \\
\hline Malaysian & 67.9 \\
\hline People Republic of China & 6.8 \\
\hline Korean & 25.3 \\
\hline \multicolumn{2}{|l|}{ Cument Smartphones } \\
\hline I phone & 25.8 \\
\hline Blackberry & 2.7 \\
\hline Nokia & 14.0 \\
\hline HTC & 0.9 \\
\hline Sony & 9.5 \\
\hline Samsung & 30.3 \\
\hline LG & 6.8 \\
\hline Motorola & 0.5 \\
\hline Others & 9.5 \\
\hline
\end{tabular}

The educational background of the students varied from Art and Humanities, Design, Sports Sciences and Health, and Education.

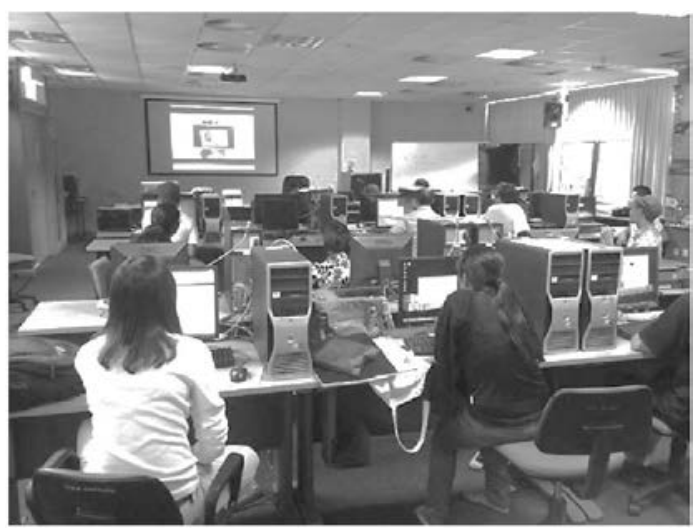

Image 5. Survey test in computer lab in Malaysia. The partial test conducted in Computer Lab Design Laboratory, Sarawak.
Part of the test were directed to youth between 20 to 35 years old to take into consideration the Malaysian government has provided incentives to youth from rural areas to upgrade $2 \mathrm{G}$ phones to smartphones. The amount of $\mathrm{RM} 200=\mathrm{KRW} 69,000$ rebate offered to the youths between 21-30 years old with monthly income of less than RM3000 = KRW1,000,000 eligible to buy any smartphones (BERNAMA, 2013). The suggested demographics then were lab-experimented by watching 4 different TV smartphones commercials representing different companies.

There are total of 221 respondents who participated in this study and tests. Based on Table 1, the respondents who participated for the test varied by gender; the number of female represented in the sample is the highest $67.9 \%$ compared to Male 32.1\%. Singles and unmarried were among majority $95.9 \%$ of the respondents. The highest percentage of the age group $81.9 \%$ were between 20 to 25 years of age, $12.2 \%$ were 26-30 years old. By nationalities, Malaysians were majority with $67 \%$, followed by South Koreans 25\%, and the minority Chinese nationals at $6 \%$. On ownership, $37.7 \%$ of the respondents owned Samsung Smartphones, which were a popular brand, followed by Apple IPhone with $25.8 \%$ and Nokia at $14 \%$.

\section{Results and findings}

Table 2. Cognitive responses categories and frequencies

\begin{tabular}{c|ccccccccc}
\hline \multirow{2}{*}{$\begin{array}{c}\text { Advertisement } \\
\text { Perception }\end{array}$} & $\begin{array}{c}\text { Nokia } \\
\text { Lumia }\end{array}$ & \multicolumn{2}{|c|}{$\begin{array}{c}\text { Samsung } \\
\text { Galaxy S III }\end{array}$} & Iphone 5 & \multicolumn{2}{c}{$\begin{array}{c}\text { LG } \\
\text { Optimus G }\end{array}$} \\
\cline { 2 - 10 } & $f$ & $\mathbf{\%}$ & $f$ & $\mathbf{\%}$ & $f$ & $\mathbf{\%}$ & $f$ & $\mathbf{\%}$ \\
\hline Attractiveness & 26 & 11.8 & 90 & 40.7 & 51 & 23.1 & 54 & 24.4 \\
\hline Believable & 32 & 14.5 & 106 & 48 & 75 & 33.9 & 8 & 3.6 \\
\hline Attitude & 39 & 17.6 & 111 & 50.2 & 47 & 21.3 & 24 & 10.9 \\
\hline $\begin{array}{c}\text { Buying } \\
\text { Intention }\end{array}$ & 26 & 16.3 & 114 & 51.6 & 55 & 24.9 & 16 & 7.2 \\
\hline
\end{tabular}

During post viewing, the participants were instructed to fill the survey forms to indicate the most viewed videos. The result was Samsung Galaxy S III advertisement video has the highest frequencies among 
the respondents compared to other advertisement videos. Table 2 shows the results in terms of frequencies and percent. Meanwhile, in Figure 3 is a summary of distribution of scores for the group of nationality based on 7 Likert scale; Malaysian, South Koreans and Chinese. The graph presented suggested Malaysians had slightly higher positive emotional perception on LG Optimus G TV advertisements scores compared to two other nationalities.

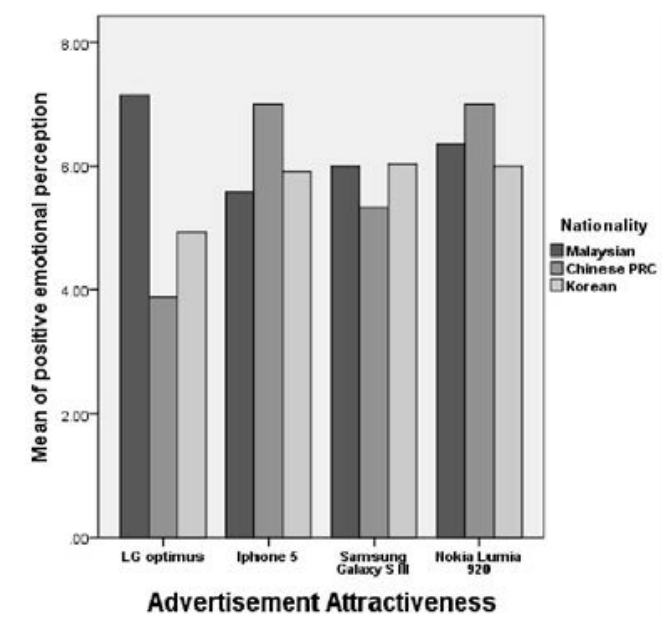

Figure 3. Distribution of scores of advertisement attractiveness based on nationality.

\subsection{Reliability and Validity}

The EFA was applied to establish reliability and validity. In earlier stage of measurement, Cronbach's alpha was implemented to analyse the internal consistency of construct and its reliability. In table 3, the recommended minimum Cronbach's alpha coefficient reliability of $>.700$ for surveys (Nunnally, 1978), (George \& Mallery, 2006) and previously a $<0.9$ consider "good". Cronbach's Alpha was used to test reliabilities of each variables and factor loadings. The initial attempted results were not satisfactory due to inconsistency of the several items in Attitudes towards Ads and shown a weak Cronbach's a of .565. Removal of items Attractive, Positive emotional response and confusing were employed toimprove the reliability of a parentheses Attitude towards Ads results. The modification improved the results in Table 3, reliability test was satisfied as a results shown Attitude towards Ads were .800 , and while Attitude towards Brand indicates substantial at .842 and Purchase Intention were .806 .

Table 3. Consumer attitudes based on Cronbach $\alpha$ Attitude towards Advertising2)

\begin{tabular}{|c|c|c|}
\hline \multicolumn{3}{|c|}{ Visual Advertisement Attitude } \\
\hline Attitude towards Ads $\mathbf{. 8 0 0}$ & Mean & SD \\
\hline beautiful & 5.71 & 1.19 \\
\hline It attracts attention & 5.20 & 1.45 \\
\hline Ads is well made & 4.26 & 1.07 \\
\hline Ads is original & 4.10 & 1.29 \\
\hline Ads tells me something new & 4.08 & 1.18 \\
\hline interesting & 4.12 & 1.24 \\
\hline $\begin{array}{l}\text { Need to watch frequently to } \\
\text { know exactly about }\end{array}$ & 3.51 & 1.44 \\
\hline Attitude Towards Brand $\mathbf{. 8 4 2}$ & Mean & SD \\
\hline recommend this brand to others & 4.16 & 1.13 \\
\hline Brand is really something for me & 3.99 & 1.31 \\
\hline Purchase Intention $\mathbf{. 8 0 6}$ & Mean & SD \\
\hline very likely will buy & 4.14 & 1.11 \\
\hline good decision to buy & 4.01 & 1.13 \\
\hline
\end{tabular}

EFA analysis was conducted to examine the validity of the measurement models. The overall fit of the EFA models were measured by using common parameters, such as chi-square, goodness of index (GFI), comparative fit index (CFI), ratio of chi-square to degrees of freedom $x^{2} / d f$, and root mean square error of approximation (RMSEA). As a rule of thumb based on Table 5, the recommended cutoff value for GFI, NFI, and CFI is $>.90$, and the acceptable threshold level for RMSEA is $<08$ (Hu \& Bentler, 2009). The first measurement model fit were very weak based on table $4\left(x^{2}=109.4, d f=27\right.$, $x^{2} / d f=44$, RMSEA $=.082$, GFI $=.911$, CFI $=.941$, NFI $=$ .906) from EFA, The measurement model shown and $x^{2} / d f=44$ value considered large, as well as RMSEA were not in acceptable value was $>.08$. As far as model fit is concern, the GFI, NFI and CFI indicated good fit.

2) Table and item presented of the initial results were measured based on seven Likert-scale. Higher mean score indicated towards stronger agreement with the statement, Value of $>.700$ (Nunnally, 1978) in parentheses are in Cronbach's were suggested acceptable. 
Table 4. CFA model testing and structural model results with parameter estimates

\begin{tabular}{cccccccc}
\hline Model & $x^{2}$ & $d f$ & $x^{2} / d f$ & RMSEA & GFI & NFI & CFI \\
$\begin{array}{c}\text { Measurement } \\
\text { Model }\end{array}$ & 109.2 & 44 & 2.48 & .082 & .911 & .906 & .941 \\
$\begin{array}{c}\text { Preliminary } \\
\text { Model }\end{array}$ & 72.3 & 42 & 1.72 & .057 & .937 & .937 & .972 \\
$\begin{array}{c}\text { Structure } \\
\text { Final Model } \\
\begin{array}{c}\text { Structure } \\
\hline\end{array}\end{array}$ & 48.05 & 27 & 1.77 & .060 & .949 & .954 & .979 \\
\hline
\end{tabular}

The second model structure (Initial Structure) were fit than the final structural model, however the initial structure has convergent validity problem due to AVE value were below .5 as shown in Table 5. Convergent validity and discriminant validity was employed by examining construct loadings and construct reliability (Peter, 1981). The initial results were not satisfactory due to low factor loading of variables, the removal of the items beautiful. The results of construct loadings were significant $(\mathrm{p}<001)$ and above the recommended value, that is, 0.7. Average variance extracted AVE was also employed to assess convergent and discriminant validity.

Table 5. Summary of Factor loadings, Average Variance Extracted and Composite Reliability3)

\begin{tabular}{|c|c|c|c|}
\hline Factor & $\begin{array}{l}\text { Std. Factor } \\
\text { Loadings }\end{array}$ & (AVE) & (CR) \\
\hline \multicolumn{4}{|l|}{ Attitude towards Ads } \\
\hline Ads is well made & .796 & 0.500 & 0.832 \\
\hline Ads is original & .782 & & \\
\hline Ads tells me something new & 662 & & \\
\hline This Ads is interesting & .630 & & \\
\hline $\begin{array}{l}\text { Need to watch frequently to } \\
\text { know exactly about }\end{array}$ & .649 & & \\
\hline \multicolumn{4}{|l|}{ Attitude Towards Brand } \\
\hline Will recommend this brand to others & .885 & .774 & .885 \\
\hline $\begin{array}{c}\text { Brand is really something for me } \\
\text { Purchase Intention }\end{array}$ & .874 & & \\
\hline Very likely will buy & .892 & .729 & .843 \\
\hline It's a good decision to buy & .814 & & \\
\hline
\end{tabular}

3) Results using Fornell and Larcker et al (1981) discriminant validity and using Stat tools by (Gaskin, 2012). Note: AVE results shown significant except Attitude towards Ads, nonetheless the limit thresholds of .5 .
As shown in Table 5, all AVE exceeded the recommended cutoff point of .5(Bagozzi \& Yi, 1988), however Attitude towards Ads met suggesting convergence validity was satisfied. Also, AVE for each construct was greater than correlation coefficients for corresponding inter-constructs, which confirms validity, this was proved using the similar formula to (Fornell \& Larcker, 1981) and employment of stat tools by (Gaskin, 2012). As shown in table 5 , all the factors were above recommended thresholds of .60 and CR above .8 .

\subsection{Structural Model Testing}

After the overall measurement model was found to be acceptable, the structural equation model was instigated to examine the relationship among the studied constructs. It was tested with the entire sample of 221. It was specified based on the hypotheses proposed. The results of SEM analysis are depicted in Figure 4.

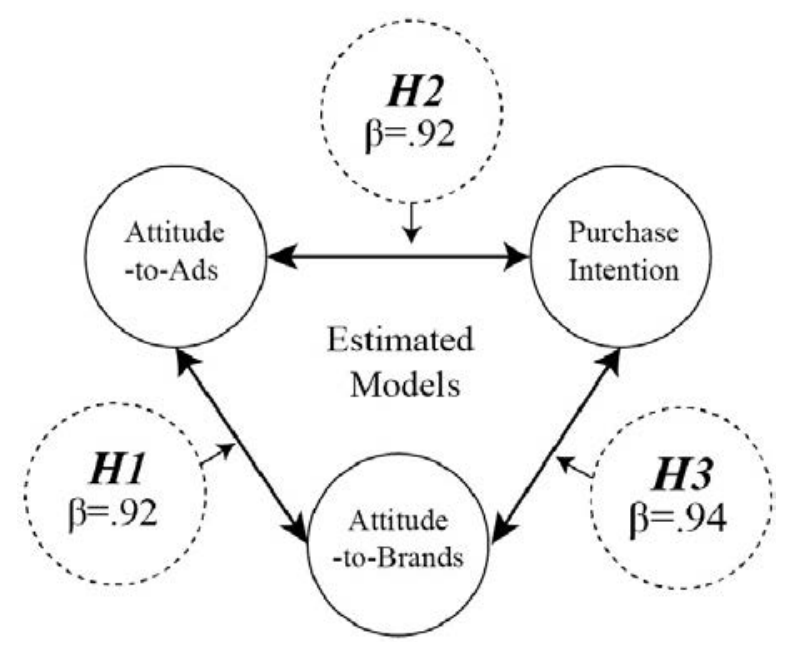

Figure 4: Results of Attitude towards Ads estimate models.4)

The fitness indices were shown table 5. The initial model structure fails to fit due to high RMSEA value, the further exploratory analysis was initiated with the removal few factor loadings were below than .6 that effected the Composite reliability. Those items were removed due to

4) Notes: Model fit Statistics: $x^{2}=48.057, d f=27, p$-value $=.008$, RMR $=0.04$, GFI $=0.95$, AGFI $=0.92$, RMSEA $=0.06$, CFI $=0.98$. Each factor loadings showing high loadings .6-.8. 
low factor includes Beautiful (The Ads were beautiful)

.43, Attracts attention .55. By removing these items, as a result, drastically improves the structural model fitness. GFI, AGFI were significantly improved above .9. The final models shows adequate model fitness of $\left(x^{2}=\right.$ 48.057, $p$-value $=.008, \quad \mathrm{RMR}=0.04, \quad \mathrm{GFI}=0.95, \quad$ AGFI $=0.92$, RMSEA $=0.06$, CFI $=0.98$ ).

\subsection{Hypothesis Testing and Assessment}

The proposed hypotheses were administered using series of regression analysis in SEM with maximum likelihood estimation. The outcome of overall model, including the estimates of the structural coefficients provide the evidence value to supported hypotheses. Hypotheses were tested by examining the significance level, the path direction and its magnitude of coefficient between independent variables and the dependent variable. Results are summarized in the Figure 5.

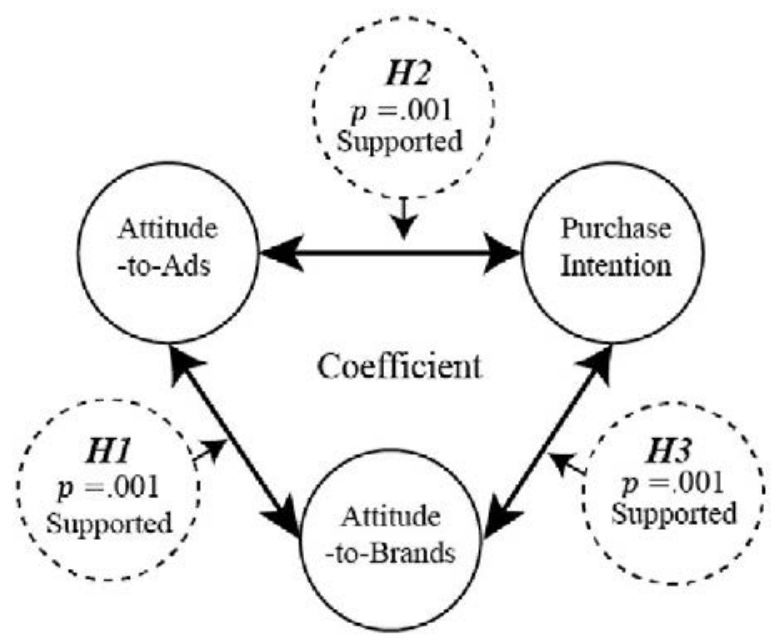

Figure 5: Results of Hypothesis testing.5)

All hypothesized relationships were significant level of ( $p=<.001$ ) and correlation path to intention to purchase, and brand and intention to purchase and promotion intention to purchase path, were significant at .001 .

5) Employment of regression analysis, SEM with maximum likelihood estimation to obtain structural correlation of the overall models, the results of two-tailed test, were less $p=<.001$.

\section{Conclusion,}

This study reveals that all three paths have consistently high coefficient path that was above $(>=0.8)$ which was supported by each correlation factors. Creative managers have to select content, based on three factors to improve influence of purchase intention and attitudes. The suggested test outcome implies whether the change of viewer's attitude towards the advertisements, and the correlational attitude towards the brand itself was the causal factor.

The initial demographic samples taken from Malaysia, produces interesting outcome of heterogeneous market demand, culture and races in comparison to consistent results from South Korea. This is due the fact that Samsung, Nokia and Sony were considered trusted brands in Malaysia.

In conclusion, structural equation study is valuable tool, known for its benefit for marketing and strategic research. In this case, the tool has been implemented specifically for managerial and creative manager's practices. Second, the particular method has it purposes to improve Purchase intention and Attitude towards the Ads.(Huang, So, \& Liu, 2012) They suggest that creative managers recommend to employ SI Sharing Intention as consideration in production to obtain advertising effects. In addition, previous research by the author of SI contend that the theory has successfully tested, among similar sample of youths, due to the current trend of sharing video content through social media in the internet.

\section{Limitation of research and Future Research.}

This study was conducted using college students as research samples. The majority of the sample population age was between the ages of 19 to 27. The initial survey results from Malaysian respondents of this age owned two smartphones. In addition, the information supports the 
national survey conducted on smartphones users in Malaysia and Korea which revealed the increase to surpass 58\%, 25 million users in Korea and 27\% smartphone penetration in Malaysia in 2012. Nevertheless, the study should extend further attention to older age groups participants, such as ranging from 35 to 40 years old, and 40-68 years old. This would be significant to identify consumers of different age groups and their attitude towards advertisements. Further, based on the correspondent smartphones owner, Sony Smartphones owners are slightly 3.5\% higher than LG phones. Therefore, the Sony advertisements should be added to the questionnaire.

The current research was to identifying the Structural Modeling via CFA (confirmatory factor analysis). Initially, the researcher was unable to identify the underlying structure of the hypothesis factor and all the supporting variables to be a structural model. Due to these conditions, EFA (exploratory factor analysis) was implemented to create structural model. The result of the initial attempt were not satisfactory due to inconsistency of the several items in Attitudes towards Ads and showed a weak Cronbach's a of .565. Removal of items Attractive, Positive Emotional response and confusing were done toimprove the reliability of a parentheses Attitude towards Ads results.Further, the initial model structure fails to fit due to high RMSEA value, the further exploratory analysis was initiated with the removal few factor loadings which were below .6 that affected the Composite reliability. Due to low factor some items were removed, such as 'Beautiful' (The Ads were beautiful) with .43, 'Attracts attention' .55 load factors respectively. By removing these items drastically improved the structural model fitness.

Nevertheless, this study does not specifically examine the method involving occurring creative process, while the creative managers designing creative visuals. There are also issues of the visual credibility to be put into consideration, such as depiction of culture and brands in the Ads. In fact, these factor plays significant role on improving the attitude of the audience. Therefore, the content element is the priority issue since the outcome will affect the purchase intention and the brand image. This is a critical role for the advertising manager's, creative team, the media strategist to formulate a content from the insights which derived from this structural model.

\section{Reference}

Advertising Trends for 2012. (2012, January 6). Retrieved from Ai Insite - The Art Institute Insite: http://insite.artinstitutes.edu/advertising-trends-for-2012 $-67009 . a s p x$

APPLE. (2013, March 11). Apple - iPhone 5 - TV Ad Brilliant. Retrieved 11 23, 2012, from Apple Youtube Channel: http://www.youtube.com/watch?v=nvKyYeJJYwM

Bagozzi, R. P., \& Yi, Y. (1988). On the evaluation of structural equation models. Journal of the Academy of Marketing Science, 74-94.

BERNAMA. (2013, January 5). The Star Online, News, Nation. Retrieved February 20, 2013, from The Star:

http://thestar.com.my/news/story.asp?file=/2013/1/5/nat ion/20130105204554\&sec=nation

Chattopadhyay, A., \& Basu, K. (1990). Humor in advertising: the moderating role of prior brand evaluation,. Journal of Marketing Research.

Compeau, L. D., Grewal, D., \& Monroe, K. B. (1998). Role of prior affect and sensory cues on consumers affective and cognitive responses and overall perceptions of quality. $y$. Journal of Business Research, 42, 295 - 308.

De Pelsmacker, P. D. (1998). Advertising characteristics and the attitude towards the ad - a study of 100 likeable TV commercials. Marketing and Research Today, pp. 166 -179. , 27(4).

De Pelsmacker, P., \& Geuens, M. (1996). The communication effects of warmth, eroticism and humour in alcohol advertisements. Journal of Marketing Communications, 2(4), 247 - 262. 
Fishbein, M. (1963). An investigation of the relationships between beliefs about an object and the attitude toward the object. Human Relations, 233-240.

Fishbein, M., \& Azjen, I. (1974). Attitudes towards objects as predictors of single and multiple behavioral criteria. Psychological Review, 59-74.

Fishbein, M., M., \& Ajzen, I. (1975). Belief, attitude, intention, and behavior: An introduction to theory and research.

Fornell, C., \& Larcker, D. F. (1981). Evaluating structural equation models with unobservable variables and measurement error. Journal of Marketing Research 18, 39-50.

Gaskin, J. (2012, 12 3). Stats tools package. Provo, Utah.

George , D., \& Mallery, P. (2006). SPSS for Windows step by step. Boston: Allyn \& Bacon.

Hu, L. T., \& Bentler, P. M. (2009). Cutoff criteria for fit indexes in covariance structure analysis: Conventional criteria versus new alternatives. Structural Equation Modeling, 6(1), 1-55. 6:1, 1-55.

Hu, L.-T., \& Bentler, , P. M. (1998). Fit indices in covariance structure modeling: Sensitivity to underparameterized model misspecification. Psychological Methods, Vol 3(4), 424-453.

Huang, J., So, S., \& Liu, X. (2012). Attitude Toward the Viral Ad: Expanding Traditional Advertising Models to Interactive Advertising. Journal of Interactive Marketing 27, 36-46.

Hwang, J., \& Hyun, S. S. (2011). The Antecedents and Consequences of Brand Prestige in Luxury Restaurants. Asia Pacific Journal of Tourism Research.

Janssens, W., \& De Pelsmacker, P. (2005). Advertising for New and Existing Brands: The Impact of Media Context and Type of Advertisement. Journal of Marketing Communications.

LG Mobile. (2012, September 30). LG Optimus G 옵 티머스 $G$ 광고 First LTE smartphone with Qualcomm, Snapdragon S4 Pro Quad Core, Optimus $G$ brings dynamic performance in style. Retrieved from Youtube LG Mobile: http://www.youtube.com/watch?v=GGnkL7M18rI

Lutz. (1985). Affective and Cognitive Antecedents of
Attitude toward the Ad: A Conceptual Framework. Hillsdale, New Jersey: Lawrence Erlbaum Associate.

Lutz, R. J., MacKenzie, S. B., \& Belch, G. J. (1983). Attitude toward the ad as a mediator of advertising effectiveness: Determinants and consequences. Advances in Consumer Research 10, 532-539.

MacKenzie, Scott, B., \& Lutz, R. J. (1989). An empirical examination of the structural antecedents of attitude toward the ad in an advertising pretesting. Journal of Marketing, 53, 48-65.

Nokia. (2012, November 26). Work on the go with the Nokia Lumia 920 and Microsoft Office. Retrieved from Nokia Brand Channel: http://www.youtube.com/watch?v=vREZxmTODWI

Nunnally, J. (1978). Psychometric Theory,. New York:: McGraw-Hill.

Ohanian, R. (1990). Construction and validation of a scale to measure celebrity endorsers' perceived expertise, trustworthiness, and attractiveness. Journal of Advertising , 19(no. 3), 39 - 52.

Peter, J. P. (1981). Construct validity: A review of basic issues and marketing practices. Journal of Marketing Research.

Pornpitakpan, C. (2003). The effect of celebrity endorsers' perceived credibility on product purchase intention: The case of Singaporeans. Journal of International Consumer Marketing. 16(2:), 55 - 74.

Pyun, D. Y., Kwon, H. H., Chon, T. J., \& Han, J. W. (2012). How does advertising through sport work? Evidence from college students in Singapore. European Sport Management Quarterly, 43-63.

Rosenberg, M. J., \& Hovland, C. I. (1960). Cognitive, affective, and behavioral components of attitudes. New Haven: Yale University Press.

Samsung Mobile. (2012, June 11). [GALAXY S III] Official TV Commercial - 30-second version. Retrieved from Official global channel of Samsung Mobile:

http://www.youtube.com/watch?v=qGfV6uh3kTs

Swaminathan, V. (1996). The evolution and antecedents of transformational advertising: a conceptual model, Advances in Consumer Research. 49 - 55.

Unnava, H. R., \& Sirdeshmukh, D. (1994). Reducing 
24 Ahmad Azaini Manaf - Lee Sung-Pil

Competitive Ad Interference. Journal of Marketing Research Vol. 31, 403-411.

Weinberger, M. G., \& Gulas, C. S. (1992). The impact of humor in advertising - a review,. Journal of Advertising(18), 35.

Received : 2013.10.18

Revised : 2014.04.17

Accepted : 2014.05.14 